\title{
RELAÇÕES ENTRE TAREFAS E ATIVIDADES EM UM CURSO ONLINE DE LÍNGUA ADICIONAL
}

\section{EXPLORING THE INTERTWINING BETWEEN TASKS AND ACTIVITIES IN AN ONLINE ADDITIONAL LANGUAGE COURSE}

\author{
Gabriela da Silva Bulla ${ }^{1}$, Lia Schulz ${ }^{2}$
}

\begin{abstract}
RESUMO: Neste artigo, exploramos as complexas relações entre tarefas e atividades pedagógicas, sendo estas inerentes ao âmbito da execução de um curso e aquelas, ao âmbito do planejamento. Os dados analisados se inserem em um curso inteiramente online de português para falantes de espanhol e foram gerados por pesquisa-ação, com observação participante e gravação de materiais e atividades realizadas nos ambientes digitais daquela edição do curso (Moodle e Skype). Refletimos sobre modos de atualização das noções de gêneros do discurso, letramentos e aprendizagem enquanto práticas sociais tanto no design educacional quanto nas ações sociais dos participantes do curso, explicitando a relevância da distinção entre tarefa e atividade para o design de cursos e para a formação de professores que desejam atuar em cursos de línguas adicionais a distância.
\end{abstract}

PALAVRAS-CHAVE: design educacional; ação social; gêneros do discurso; letramentos.

\begin{abstract}
In this article, we explore the complex relationships between pedagogical tasks and activities, being the former in the scope of course planning, and the latter in the scope of course implementation. The analyzed data are part of an entirely online Portuguese course for Spanish speakers and were generated by action research, with participant observation and recording of materials and activities carried out in the digital environments of that edition of the course (i.e. Moodle and Skype). We reflect on ways of updating the notions of speech genres, literacies and learning as social practices both in the design and in the social actions of the course participants, highlighting the relevance of the distinction between task and activity for course design and for online teacher education.
\end{abstract}

KEYWORDS: educational design; social action; discourse genres; literacies.

\section{Introdução}

Nas últimas décadas, a educação a distância (EAD) tem se tornado uma modalidade mais frequente para ensino e aprendizagem de línguas no Brasil (COLLINS; FERREIRA, 2004; SCHLATTER et al., 2007; BULLA et al., 2009; BRAGA, 2013)³. Diversos autores têm

\footnotetext{
${ }^{1}$ Doutora em Letras pela Universidade Federal do Rio Grande do Sul (UFRGS). Coordenadora Geral do PPE UFRGS.

${ }^{2}$ Doutora em Letras pela Universidade Federal do Rio Grande do Sul (UFRGS). Professora Adjunta da UFRGS.

${ }^{3} \mathrm{Na}$ atual conjuntura mundial de crise pelo covid-19, a EAD (ou uma versão emergencial de ensino remoto) assumiu um caráter urgente, tornando-se a modalidade de educação majoritária na pandemia, e revelando a falta de
} 
pesquisado não apenas sobre como se dá a aprendizagem em ambientes virtuais (FONTES, 2002; POLONIA, 2003; TELLES, 2009; BULLA, 2014), mas também sobre como o próprio ambiente e o modo como as tarefas são propostas possibilitam e configuram essa aprendizagem (BULLA et al., 2012; PAIVA et al., 2012; FREIRE, 2013). Há ainda a necessidade de ampliação de pesquisas sociológicas sobre as relações entre design educacional e atividades situadas em cursos online de línguas adicionais ${ }^{4}$, conforme proposto em Bulla (2014), especialmente aqueles arquitetados para a aprendizagem pela interação social em ambientes digitais, com o que procuramos contribuir.

O presente artigo, portanto, tem como objetivo refletir sobre as relações entre tarefas, inerentes ao âmbito de planejamento, e atividades pedagógicas, partes do âmbito da execução, em um curso de língua adicional realizado inteiramente online. Ao explorarmos tais relações, discutimos sobre modos de atualização das noções de gêneros do discurso, letramentos e aprendizagem enquanto práticas sociais tanto no design educacional quanto na realização de um curso online, demostrando a complexidade do trabalho de planejamento e implementação de um curso para aprendizagem de língua adicional pela interação em ambientes digitais.

Os dados aqui analisados foram gerados em uma pesquisa-ação (envolvendo observação participante e gravação de materiais e atividades online), desenvolvida por uma das autoras deste artigo (BULLA, 2014), durante a primeira edição do Curso de EspanholPortuguês para Intercâmbio (CEPI) da Universidade Federal do Rio Grande do Sul/UFRGS (CEPI-Português/UFRGS), ocorrida em janeiro e fevereiro de 2011. Criado em 2007 em uma parceria entre UFRGS e duas universidades argentinas (Universidade Nacional de

\footnotetext{
formação em EAD de grande parte do corpo docente no Brasil, a falta de infraestrutura para sua realização com qualidade, a sobrecarga de trabalho do professor (que assume, sem remuneração extra, os papeis que na EAD seriam desempenhados por equipes como web designer, programador, professor-conteudista, equipe de gravação e edição, professor-ministrante, tutores, suporte técnico), as dificuldades de inclusão de alunos com alta vulnerabilidade (ampliando abismos socioeconômicos) etc. Embora os dados aqui analisados tenham sido gerados em momento anterior à pandemia, esperamos que as reflexões aqui apresentadas possam também auxiliar os professores neste período de crise

${ }^{4} \mathrm{O}$ termo língua adicional é aqui utilizado em um sentido amplo e em distinção à língua de socialização inicial (comumente chamada de língua 1 ou língua materna), ou das línguas de socialização inicial (em casos de socialização bilíngue ou multilíngue), sendo necessário ainda a contextualização das relações linguísticas (por exemplo, se a língua adicional é próxima ou distante da língua adicional etc.), sócio-históricas (em comunidades falantes da língua ou não, em escolas, em cursos livres, como requisito para cidadania, para acesso ao ensino superior etc.) e afetivas (desejo ou não de aprender a língua, motivos para aprendizagem, língua de herança familiar etc.) dos alunos com a língua adicional sendo aprendida, bem como o contexto em que essa aprendizagem se dá (em sala de aula com professor, na rua, em tandem, em ambientes digitais etc.).
} 
Córdoba/UNC e Universidade Nacional de Entre Rios/UNER), o CEPI é um curso online de Português como Língua Adicional (PLA) realizado inteiramente a distância e oferecido gratuitamente aos futuros intercambistas falantes de espanhol que estudarão na UFRGS (SCHLATTER et al., 2007; BULLA et al., 2009)5. Sendo assim, os alunos do CEPIPortuguês/UFRGS encontram-se em diferentes partes do mundo, e comumente participam desse curso de extensão antes de viajarem a Porto Alegre. O design do curso é orientado por linguagem como modo de ação social, gêneros do discurso como organizadores da participação social, e aprendizagem como uma realização intersubjetiva (SCHLATTER et al., 2007). Como é oferecido no âmbito do Programa de Português para Estrangeiros (PPE) da UFRGS, com o qual compartilha sua base teórica, o CEPI é uma instância de formação de professores de PLA e de pesquisas sobre ensino e aprendizagem de línguas adicionais a distância ${ }^{6}$.

A primeira edição do CEPI, com duração de 60h, teve como equipe uma professora de PLA em formação (estudante de graduação em Letras), um professor assistente (também graduando em Letras) e uma pesquisadora, que concomitantemente atuou como coordenadora do curso, orientadora pedagógica e suporte técnico dos professores. Os oito alunos participantes eram falantes de espanhol que haviam sido selecionados para realizarem intercâmbio na UFRGS a partir de março de 2011, e provinham de diferentes cursos, universidades e cidades na Argentina ${ }^{7}$. Neste artigo, analisamos duas tarefas pedagógicas da Unidade 2 (sobre Porto Alegre) e as atividades realizadas pelos participantes a partir delas. A primeira tarefa indicava a leitura de um site na web para informar a escrita coletiva de um texto na ferramenta wiki; e a segunda sugeria a realização de uma interação escrita via chat após a leitura dos textos produzidos pelos outros grupos. Como poderá ser observado na análise, a primeira tarefa não foi cumprida pelos alunos conforme esperado pela equipe pedagógica; já os objetivos educacionais da segunda foram atingidos. Os dois casos encadeados possibilitam reflexões sobre design de tarefas e formação de professores para atuação em cursos online.

Antes de procedermos à análise dos dados, resumimos, nas próximas seções,

\footnotetext{
${ }^{5}$ UNC e UNER possuem suas versões do CEPI para ensino de espanhol para falantes de português: CEPIEspanhol/UNC e CEPI-Espanhol/UNER, considerando que uma das características do design educacional do CEPI é a utilização de textos (dos mais diversos gêneros do discurso) do contexto local da universidade de destino.

${ }^{6}$ Pesquisas no âmbito do CEPI podem ser encontradas em www.ufrgs.br/cepi (acesso em 06 de mar. de 2020).

7 Embora a primeira edição tenha sido composta apenas por argentinos, o CEPI-Português/UFRGS recebeu diferentes grupos desde então, com alunos provenientes de países da América Latina, Caribe e Europa.
} 
pressupostos teóricos centrais para nossa argumentação. Primeiramente, discutimos os conceitos de gêneros do discurso, letramentos e aprendizagem e, em seguida, definimos tarefa e atividade, destacando as potencialidades dessa distinção para a pesquisa e a atuação educacional.

\section{Gêneros do discurso, letramentos e aprendizagem enquanto práticas sociais}

A noção de gêneros do discurso fundamenta diferentes documentos oficiais sobre educação linguística e literária no Brasil (BRASIL, 1998; RIO GRANDE DO SUL/RS, 2009). No PPE, esta é uma das noções basilares de arquiteturas curriculares para o ensino de PLA (SCHLATTER et al., 2009; KRAEMER, 2012; BULLA et al., 2019), pois parte de uma concepção de linguagem como modo de ação social (CLARK, 1996). Em uma perspectiva fundamentada por autores do Círculo de Bakhtin (BAKHTIN, 2003; VOLOSHINOV, 1973), os gêneros do discurso se referem não apenas aos modos de dizer, mas também aos modos como lidamos com o que está acontecendo ao nosso redor, pois orientam nossas ações e criam expectativas sobre o que estamos fazendo e dizendo a cada momento. Para Faraco (2009), os gêneros do discurso

ao gerarem expectativa de como serão as ações, (...) nos orientam diante do novo no interior dessas mesmas ações: auxiliam-nos a tornar o novo familiar pelo reconhecimento de similaridade e, ao mesmo tempo, por não terem fronteiras rígidas e precisas, permitem que adaptemos a sua forma às novas circunstâncias. (FARACO, 2009, p. 130)

Nesse sentido, Faraco (2009) reforça as ideias de movimento e dinamismo inerentes ao conceito de gêneros do discurso, os quais podem ser concebidos como modos sócio-históricos de dizer, participar e orientar nossas ações no mundo ${ }^{8}$. Em outras palavras, gêneros do discurso são modos (sócio-historicamente construídos e sempre atualizados localmente) de organização da participação social pelo uso da linguagem, em diferentes campos de atividade humana (BAKHTIN, 2003; VOLOSHINOV, 1973).

$\mathrm{Na}$ transposição didática dessa noção filosófica acerca de linguagem e sociedade para um ensino de línguas baseado em gêneros, destacamos que os modos de dizer devem estar, portanto, ligados às situações de comunicação e às práticas sociais que embasam tais modos, tais dizeres. Assim, a educação da linguagem cria oportunidades de aprendizagem que tratem

\footnotetext{
${ }^{8}$ Segundo Rojo (2005), essa compreensão sócio-histórica e dinâmica é chamada de gênero discursivo (aqui também referido indistintamente como gênero do discurso), se afastando de um entendimento mais formalista e estrutural do conceito, o que Rojo (2005) associa na Linguística Aplicada ao termo gênero textual.
} 
exatamente da relação ético-estética-ideológica entre uso da linguagem e os gêneros discursivos dos quais nos utilizamos para realizar ações no mundo em diferentes esferas sociais. Nos parece fundamental, ademais, como defende Britto (1997), a centralidade do acesso à escrita e aos discursos que se organizam a partir dela e, assim, o planejamento para que sejam criadas oportunidades de participação social e de acesso às práticas que envolvem a escrita.

Aliado à ideia de acesso à escrita, outro conceito central é o de letramento, entendido como "conjunto de práticas sociais que usam a escrita, como sistema simbólico e como tecnologia, em contextos específicos, para objetivos específicos” (KLEIMAN, 1995, p. 18-9). Nesse entendimento de escrita, prevalece a ideia de que tais práticas não se dão isoladamente e que a aprendizagem e o uso da escrita envolvem eventos de letramento, que são constituídos por diferentes atividades realizadas por meio de práticas sociais que envolvem a leitura e a escrita (práticas de letramento), concebidas como construções sociais variáveis e sensíveis a diferentes propósitos, contextos, comunidades, culturas (STREET, 1984; TERZI, 2001). Especialmente ao considerarmos um curso online como o CEPI, realizado integralmente em ambientes digitais, há que se considerar também as trajetórias de letramento digital dos professores e alunos. Um curso que visa promover vivências semióticas interacionais no ciberespaço também está comprometido, portanto, com a promoção do letramento digital, concebido aqui não apenas como a habilidade de usar o computador/tablet/smartphone e a internet para acessar conteúdos ("surfar na internet"), objetivo recorrente nas fases iniciais da rede (BULLA, 2014), mas também como a habilidade de interpretar, intervir e produzir conhecimento no ciberespaço (“fazer ondas na internet”) (WARSCHAUER, 2008).

Deste modo, entendemos que a aprendizagem de uma língua adicional se dá em práticas situadas de uso da linguagem que envolvem práticas específicas de acesso e uso da escrita e modos de dizer e de agir no mundo; esses modos guiam as ações realizadas a cada momento e são reconhecidos por nós dependendo do nosso repertório e do acesso a tais modos. A nossa familiaridade ou não com os modos sócio-históricos de dizer e de fazer no mundo também definirá as maneiras como lidaremos com conhecimentos novos a serem aprendidos. Portanto, quando tratamos de planejamento de aprendizagem, um dos pontos centrais é justamente descobrir o que os participantes já sabem e o que precisam aprender para poderem realizar ações no mundo por meio do uso da linguagem (SCHLATTER; GARCEZ, 
2012). Assim, o planejamento de tarefas pedagógicas que preveem ações possíveis dos participantes, o conhecimento prévio e necessário dos gêneros do discurso solicitados para executar tais ações e as trajetórias de letramentos dos participantes são elementos fundamentais dentro desta perspectiva de aprendizagem como ação conjunta e situada em interações sociais.

\section{Do design à realização de um curso: tarefa e atividade como objetos distintos}

Com base em Wiley (2002), Barab, Kling e Gray (2004), Sadykova e Meskill (2009) e Freire (2013), entendemos design educacional como "a organização geral de um curso online, seu currículo, a ordenação das tarefas, os ambientes virtuais (e suas interfaces) selecionados como suporte às atividades do curso, todos criados previamente ao início de qualquer curso online" (BULLA, 2014, p. 61). Assim, inerente ao âmbito do planejamento, conforme Schlatter et al. (2009), Bulla et al. (2009) e Bulla (2014), tarefas pedagógicas são definidas como convites, sustentados por objetivos educacionais, para que ações sejam realizadas conforme uma sugestão (expressa na própria tarefa e no encadeamento delas) de enquadramentos de atividades futuras (COUGHLAN; DUFF, 1994). Uma tarefa é um "convite para interagir com o mundo, usando a linguagem com um propósito social" (BRASIL, 2011, p. 4), é um plano de ação, um objeto discursivo em relação ao qual os participantes são convidados a agir responsivamente pela realização de atividades situadas (BULLA, 2014).

Inspiradas nas discussões de Suchman (2007) acerca das relações entre humanos e máquinas, defendemos, portanto, que tarefas pedagógicas precisam ser entendidas não como objetos discursivos completos em si, mas como dependentes das ou constituídas pelas respostas que os participantes de um curso produzem para tal tarefa (BULLA, 2014). Tais respostas devem ser observáveis nas atividades pedagógicas que eles realizam enquanto desempenham - ou não - as ações sugeridas na tarefa, pois, dependendo da resposta, os objetivos educacionais da tarefa podem precisar ser reconfigurados (BULLA, 2014). De modo complementar, porém inerente ao âmbito da implementação, atividade pedagógica é entendida como a realização da proposta da tarefa (ou de variações dessa proposta) nas ações sociais dos participantes envolvidos; são, portanto, conjuntos de ações sociais com propósitos compartilhados, novamente imprevisíveis e transformáveis (MONDADA; DOEHLER, 2004), visto o caráter situado das interações sociais. Partimos, então, para a reflexão sobre as relações 
entre tarefas e atividades em um curso online.

\section{Análise de dados}

A título de organização da análise ${ }^{9}$, primeiramente, exploramos os enunciados das duas tarefas pedagógicas do CEPI: uma via wiki (vinculada à leitura de um site) e outra via chat. Em seguida, analisamos a atividade pedagógica realizada em resposta à tarefa via wiki e, a partir da relação entre a tarefa e a atividade, articulamos aprendizagens sobre o design de tarefas implementadas nessa ferramenta e do papel do professor como necessário analista de atividades em relação às tarefas, visando à ponderação acerca da (re)configuração dos objetivos educacionais e da atualização do construto teórico que embasa o curso. Por fim, analisamos a atividade pedagógica realizada em resposta à tarefa via chat e, novamente com base na relação entre a tarefa e a atividade, demonstramos como a atividade pedagógica realizada pode ser entendida como um evento de letramento, atingindo objetivos educacionais da tarefa. Ao longo da análise, destacamos a importância da distinção entre tarefa e atividade também para fins de planejamento.

\section{As tarefas pedagógicas enfocadas}

A tarefa 3.1 Roteiro turístico (fig. $1^{10}$ ) sugere que os alunos realizem uma investigação sobre locais turísticos de Porto Alegre para, em grupos, escreverem um roteiro com os pontos que gostariam de visitar, configurando-se, portanto, como uma tarefa integrada de leitura e escrita. Os objetivos da tarefa eram: (a) ler textos (escritos, multimodais e/ou hipertextuais) em português (embora o nome do site sugerido esteja em inglês: City Brazil) sobre turismo em Porto Alegre, (b) interagir com colegas do grupo para planejarem a escrita coletiva, (c) escrever via wiki, em português, um texto do gênero do discurso roteiro turístico, de autoria compartilhada, tendo como interlocutores os colegas de CEPI, e (d) cumprir uma etapa preparatória para a participação na atividade seguinte via chat (tarefa 3.2).

\footnotetext{
${ }^{9}$ Uma versão preliminar da análise destes dados pode ser encontrada em Bulla (2014).

${ }^{10}$ Os participantes são referidos por pseudônimos, com exceção da pesquisadora.
} 
Figura 1

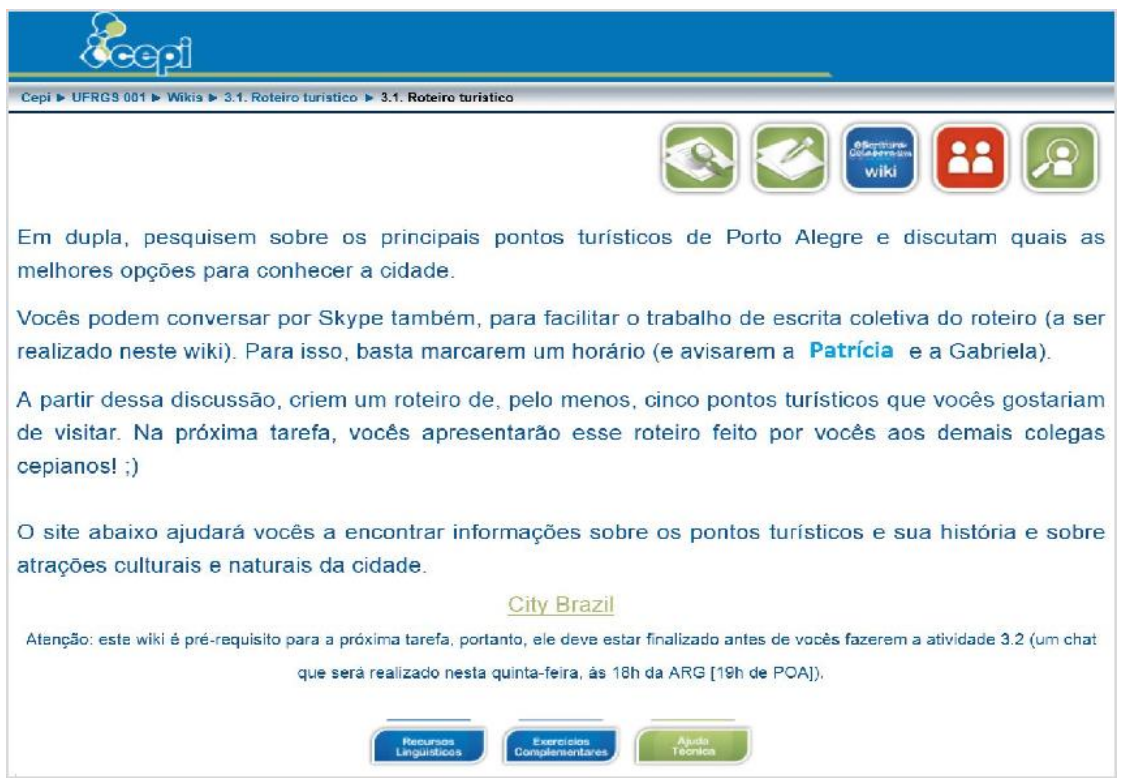

A tarefa 3.2 Passeio preferido (fig. 2) sugere aos alunos a realização de três ações: (i) antes de entrar no chat do Skype, ler o roteiro criado pelo outro grupo no wiki, (ii) no chat, fazer, no mínimo, as três perguntas (listadas na tarefa) aos colegas sobre locais turísticos, e (iii) responder as perguntas dos colegas. Os objetivos educacionais da tarefa podem ser resumidos em: (a) interagir em português, (b) construir e compartilhar conhecimentos sobre pontos turísticos de Porto Alegre, e (c) avaliar e se posicionar sobre opções turísticas. O gênero do discurso sugerido na tarefa seria, portanto, conversa com colegas.

Figura 2

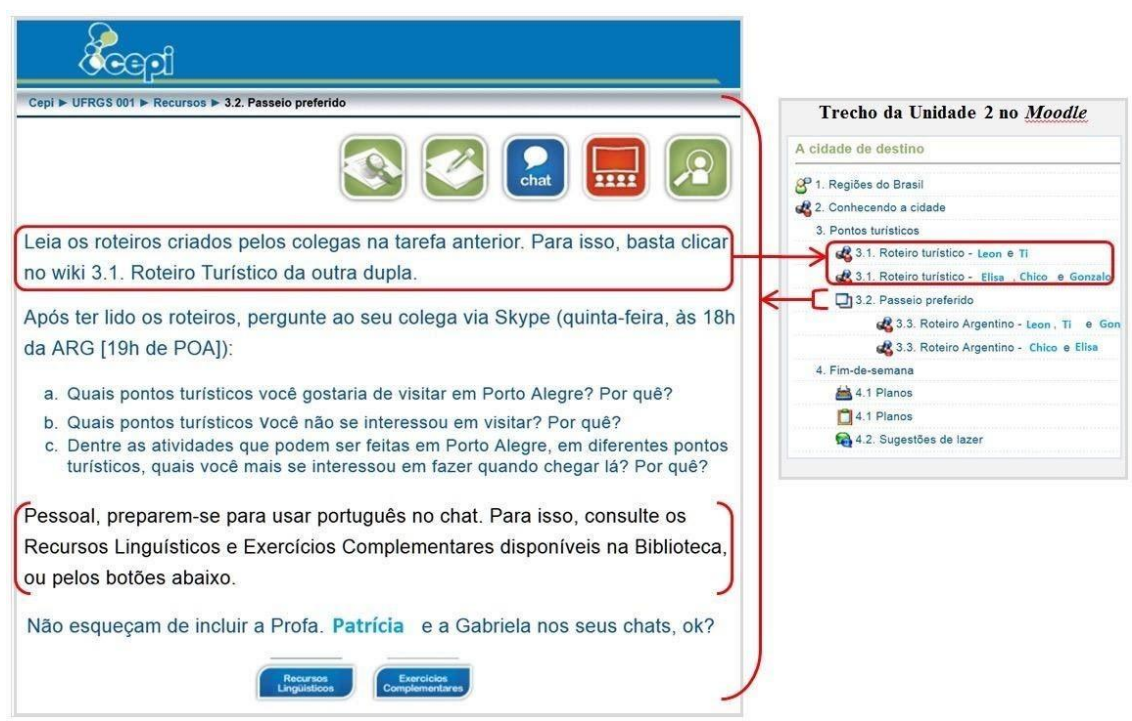


As duas tarefas foram propostas no cronograma da Semana 2, tendo sido antecedidas por uma discussão via fórum sobre suas expectativas para o intercâmbio; uma videoconferência para avaliação e fechamento da Unidade 1; um fórum sobre regiões do Brasil; e um wiki com dados gerais sobre Porto Alegre (cada grupo sendo responsável por encontrar diferentes informações). Na Semana 1, os alunos realizaram atividades com o objetivo de se conhecerem e se familiarizarem com os ambientes digitais daquela edição do CEPI (Moodle e Skype).

\section{Reconfigurando objetivos educacionais da tarefa a partir da análise da atividade pedagógica: de uma tarefa de leitura e produção textual para uma tarefa apenas de leitura}

Para discutirmos a relação entre a tarefa 3.1 e a atividade realizada via wiki, apresentamos apenas as versões finais dos textos dos dois grupos (fig. 3), embora tenham sido construídos em diferentes versões. As finais são suficientes para discutirmos sobre elaboraçãode tarefas de leitura e produção textual orientadas por gêneros do discurso, promoção de letramentos, e reconfiguração de objetivos pedagógicos a partir da análise das atividades. 
Figura 3

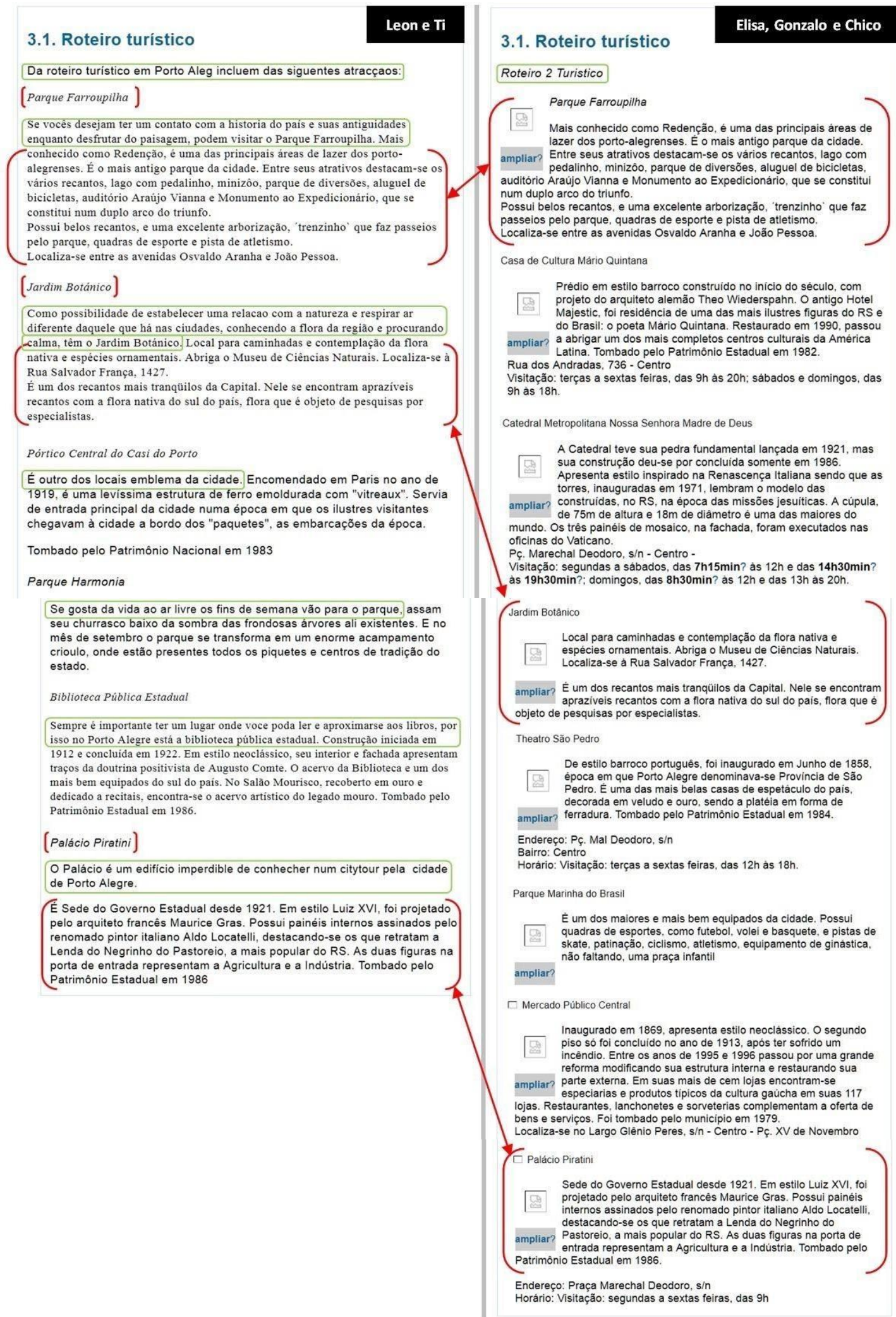

Ao analisar rapidamente o texto do wiki de Elisa, Gonzalo e Chico, apresentado na coluna da direita da fig. 3, é inevitável o questionamento acerca da autoria daquele texto: há 
figuras indisponíveis para a visualização e links quebrados. Sendo assim, o texto havia sido copiado de um site. Retomando o enunciado da 3.1 (fig. 1), vale lembrar a indicação de consulta à seção Atrações Turísticas de Porto Alegre, do site City Brazil, como única fonte de pesquisa fornecida no design educacional (o que não impediria os alunos de procurarem outras fontes, embora a indicação de uma fonte pelo professor garanta maior legitimidade e confiabilidade em relação às demais do ciberespaço, apontando para a importância da curadoria do professor). Na fig. 4, reproduzimos parte do site sugerido e alguns hiperlinks.

Figura 4

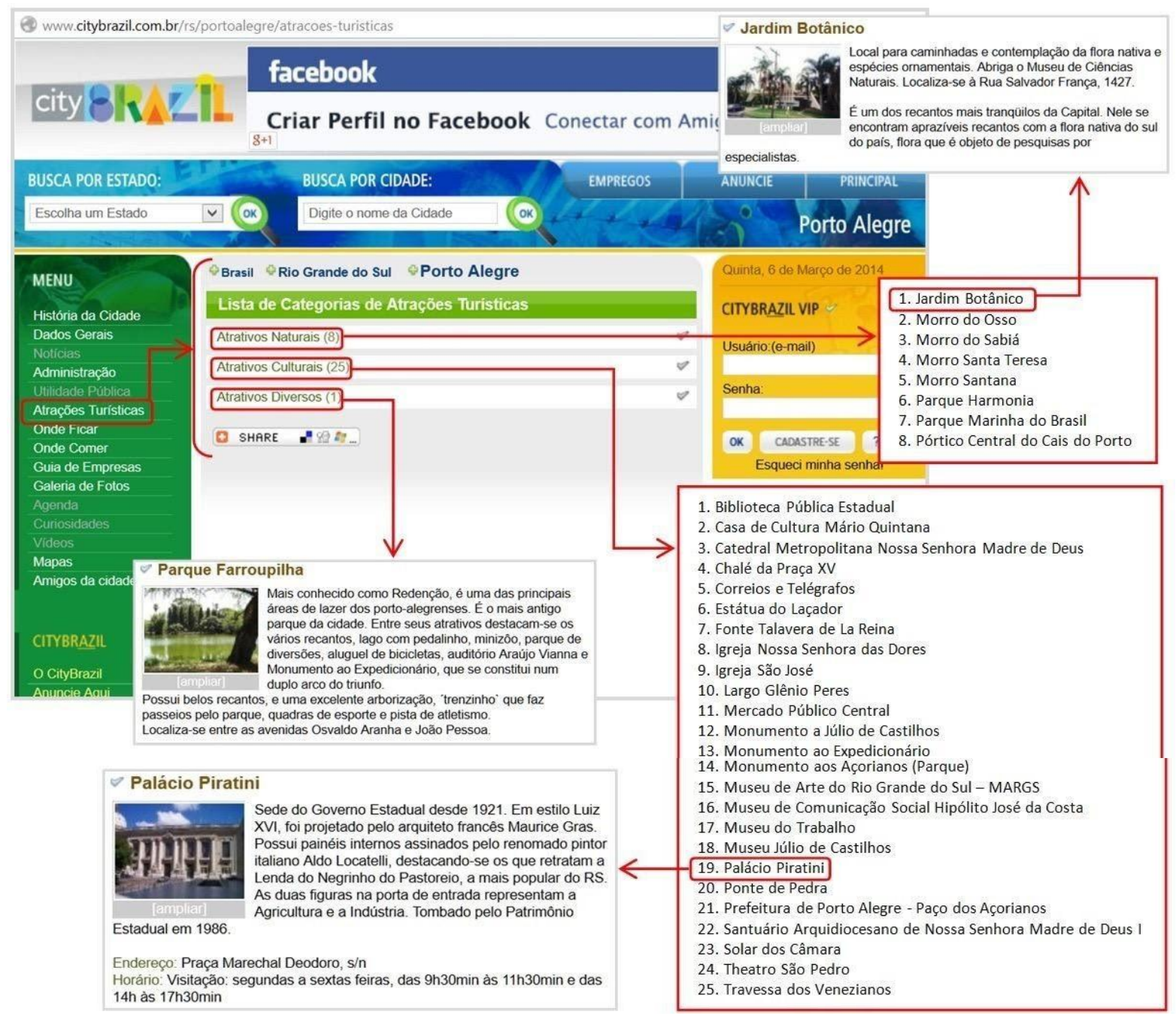

Como pode ser observado, o site fornece 34 atrações turísticas, e os dois grupos não copiaram e colaram em seus wikis todas as atrações (fig. 3 e 4). Leon e Ti selecionaram seis atrações (a 3.1 solicitava pelo menos cinco), e Elisa, Gonzalo e Chico escolheram oito. A seleção e cópia de uma mesma fonte de pesquisa teve também como implicação a presença de três parágrafos idênticos (Parque Farroupilha, Jardim Botânico e Palácio Piratini) nos dois 
wikis, o que demonstra convergência entre os participantes dos grupos em termos de preferências de visitação, além de confirmar a utilização de procedimentos de cópia e cola do site, não antecipados no design educacional do CEPI.

A professora e a equipe pedagógica discutiram, então, ações responsivas. No Fórum de Dúvidas (espaço para comunicações gerais), a professora postou instruções relativas à citação de trechos de autoria de outras pessoas (uso de aspas e explicitação de fontes) e, ao final de cada texto nos wikis, a professora também postou mensagens incentivando os alunos a tentarem escrever um roteiro de autoria deles, com suas palavras e sem cópias de textos de outras pessoas.

Além de abordar a problemática das cópias, a professora e a equipe pedagógica também discutiram a adequação dos textos dos alunos ao gênero roteiro turístico, o que se desdobrou em uma nova análise da adequação da tarefa à noção de gêneros do discurso. Desse modo, nos wikis, a professora também forneceu links de exemplos de roteiros disponíveis online, em uma tentativa de possibilitar, ainda que tardiamente, reflexões sobre o gênero do discurso solicitado. Em resposta às orientações da professora, Leon e Ti escreveram os trechos destacados em verde na fig. 3, mantendo as cópias sem aspas e fonte; o outro grupo não editou seu wiki.

Ao considerar o curto espaço de tempo que os alunos tiveram para fazer a pesquisa, a ausência de análise e reflexão sobre como se pode escrever o gênero roteiro turístico, bem como o próprio convite a escrever sobre lugares que os alunos não conheciam (um roteiro sobre suas cidades provavelmente teria sido mais produtivo), a professora e a equipe pedagógica passaram a entender os wikis da 3.1 como espaços para compartilhamento de leituras feitas e definição de preferências do grupo, não mais como espaços para a escrita autoral de roteiros turísticos - entendimentos esses discutidos com os alunos, obviamente, considerando a seriedade do tratamento do crime de plágio que assola a educação na contemporaneidade. Essa mudança de enquadramento com relação à tarefa não foi um processo simples para a equipe pedagógica, especialmente considerando o grande esforço coletivo para que os objetivos da tarefa fossem alcançados. Assim, reconfigurados os objetivos da 3.1 em termos de expectativas pedagógicas, os wikis da 3.1 foram entendidos como mais uma preparação para a participação no chat da 3.2, assim como os wikis da Semana 1 com informações gerais sobre a cidade.

Em suma, a análise da relação entre a tarefa 3.1 e a atividade realizada via wiki 
(atreladas a notas acerca da equipe pedagógica) evidencia a importância da realização do trabalho de leitura, análise de textos e estudo do gênero do discurso como etapa anterior à produção textual, conforme proposto em Dolz et al. (2004), Rojo (2005), entre outros. Sem esse trabalho, considerando que os alunos possam não ter relação com práticas de letramento envolvendo tal gênero, é possível que não saibam como produzir o gênero solicitado ou que procedam como o caso apresentado.

Conforme discutido em Bulla (2014), a análise também reforça a necessidade de compreensão de tarefas como objetos discursivos dependentes das e constituídos pelas respostas produzidas pelos participantes do curso, respostas essas observáveis nas atividades em que se engajam e nas ações que realizam. Dependendo da resposta, os objetivos educacionais planejados podem precisar ser reconfigurados coletivamente. Nos dados, os participantes realizaram uma atividade de compartilhamento de leituras e de seleção coletiva de informações do texto-base lido, embora a tarefa tivesse sugerido a realização de uma produção escrita em conjunto. Pelos problemas identificados, os objetivos precisaram ser modificados, passando a ser compreendida como uma tarefa de leitura coletiva, cada participante aportando suas preferências.

\section{A realização da atividade pedagógica em grupo via chat como um evento de letramento vinculado ao design educacional: cumprindo a tarefa e ampliando oportunidades de aprendizagem na interação online}

A relação entre a tarefa 3.2 e a atividade realizada via chat do Skype é aqui discutida a partir de um excerto de apenas 81 linhas da interação (fig. 5), parte de um encontro com duração total de 1h10min (422 linhas), envolvendo Patrícia (professora), Daniel (professor assistente), Leon, Gonzalo e Ti (alunos), além da pesquisadora Gabriela como observadoraparticipante. Conforme demonstrado na análise, a relação entre tarefa e atividade, neste caso, se configura como um exemplo satisfatório de atualização do construto em questão (gêneros do discurso, letramentos e aprendizagem como práticas sociais) no design e nas ações sociais.

Na coluna da esquerda da fig. 5, dispomos o excerto de interação escrita via chat e, na coluna da direita, os trechos dos textos dos wikis de ambos os grupos (tarefa anterior), aos quais os participantes fazem referência em seus turnos de escrita (destaques em amarelo, azul e verde, conforme explicado na legenda da fig. 5). Considerando as referências aos wikis, 
nota-se que Ti foca praticamente em pontos turísticos incluídos no wiki do seu grupo (Ti e Leon) ou que foram selecionados por ambos os grupos; Leon se refere a lugares selecionados pelo outro grupo (Gonzalo, Elisa e Chico) e Gonzalo faz referência aos dois wikis. São, portanto, diferentes ações (Ti destaca qualidades e convida os demais a visitarem locais do seu wiki, enquanto Leon analisa locais apresentados pelo outro grupo), evidenciando que Ti e Leon operam com compreensões distintas da relação entre as tarefas 3.1 e 3.2, porém ambas sustentadas por questões de design: na 3.1, o trecho "Na próxima tarefa, vocês apresentarão esse roteiro feito por vocês aos demais colegas cepianos!" estaria mais vinculado às ações de Ti e, na 3.2, o trecho "Leia os roteiros criados pelos colegas na tarefa anterior", às ações de Leon. Afinal, por que apresentar seu roteiro na interação via chat se o outro grupo já o terá lido? Nesse sentido, teríamos, então, nova sugestão de edição da tarefa 3.1 a partir da análise das ações dos participantes na atividade realizada em resposta à tarefa 3.2.

Apesar dessas questões, os participantes conseguiram realizar a atividade pedagógica de modo a alcançarem os objetivos da 3.2. Os alunos interagiram usando a língua adicional, com interlocutores e propósitos definidos, demonstraram ter lido os wikis ao usarem recursos linguísticos com intertextualidade explícita (circulados em vermelho tanto nos turnos de escrita, quanto nos trechos dos wikis), avaliaram as suas preferências turísticas, construíram compreensões compartilhadas sobre o texto-base (site), se posicionam com relação às escolhas dos colegas e, assim, produziram relações identitárias afiliativas e desafiliativas.

Entendemos, portanto, que a compreensão do texto-base do site foi iniciada pela construção dos emergentes diários de leitura coletiva nos wikis da tarefa 3.1 , e foi complexificada na interação via chat da 3.2, fornecendo ainda aos participantes elementos de referenciação coletiva, sustentados pela pressuposição de leituras compartilhadas (e em construção) entre os participantes. 


\section{Figura 5}

Excerto de escrita-em-interaç̃o

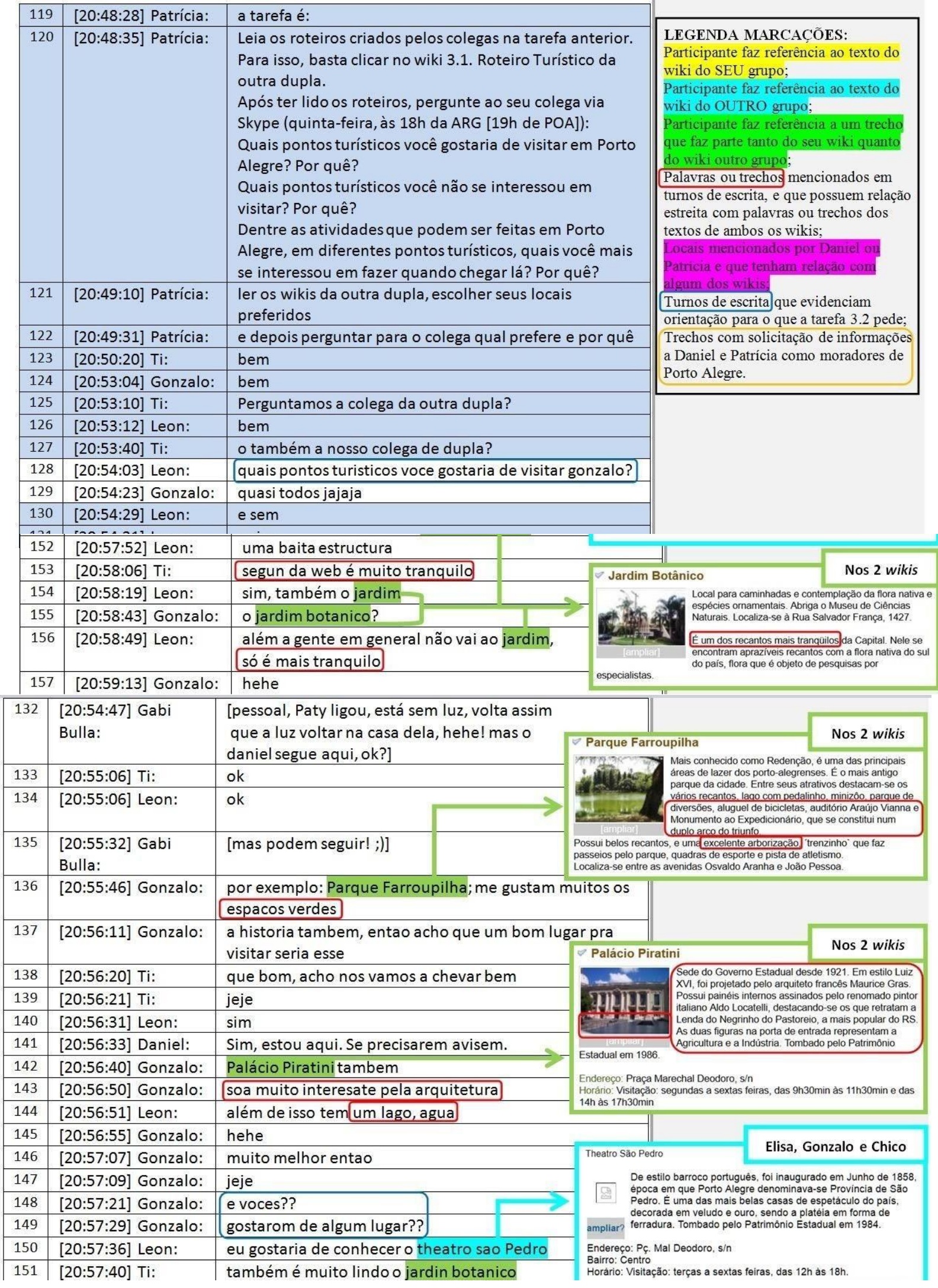
Participante faz referência ao texto do wiki do OUTRO grupo;

que faz parte tanto do seu wiki quanto estreita com palav ou trechos dos textos de ambos os wikis;

Turnos de escrita que evidenciam orientação para o que a tarefa 3.2 pede; (n) Dorácia como mores de

Relações com os wikis

\section{.}




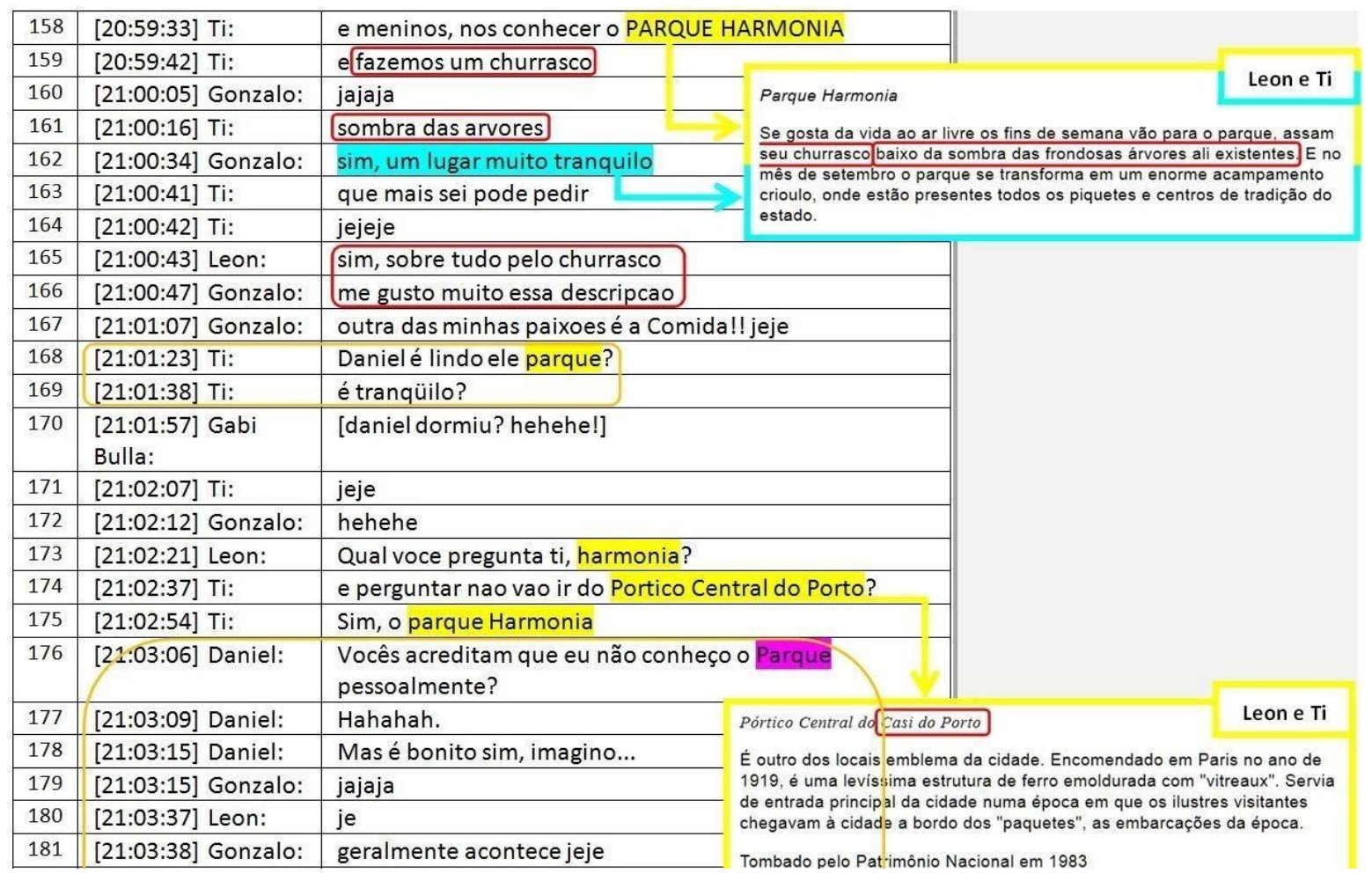

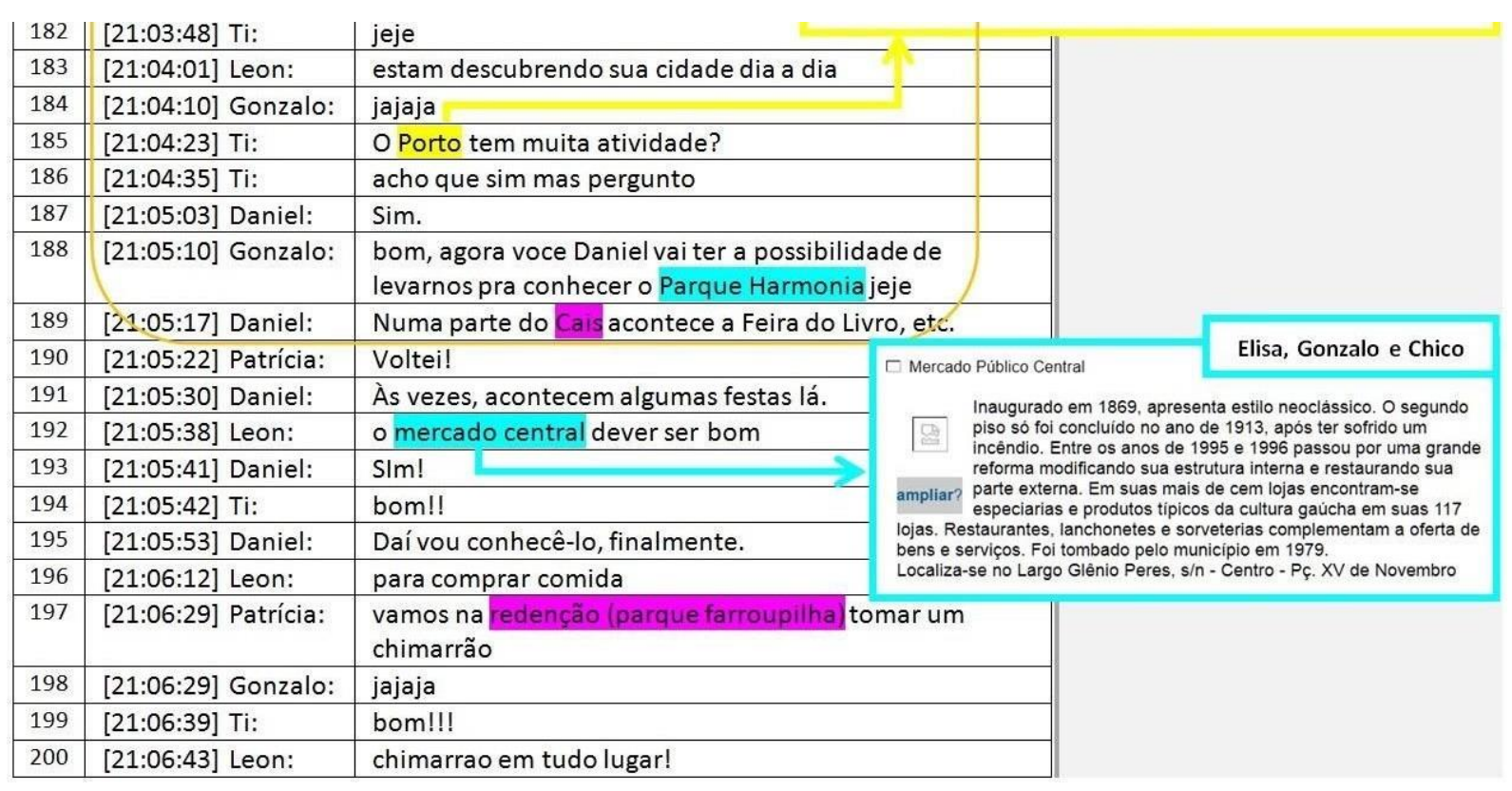

Na relação tarefa e atividade, cabe destacar ainda os turnos de escrita (circulados em azul escuro) que demonstram a orientação dos participantes para o que a tarefa 3.2 pede, bem como para a democratização do piso conversacional, de modo que todos tivessem a oportunidade de cumprir a tarefa, especialmente em relação à ação fazer perguntas aos colegas. Os participantes, então, construíram conjuntamente contextos colaborativos de aprendizagem (BULLA, 2007), nos quais todos possuem o direito e o dever de fazer parte ativamente das atividades coletivas, sendo requerida a participação de todos. $\mathrm{Na}$ 
complexidade da requisição da participação de todos, nota-se também a construção conjunta das identidades de locais, que supostamente conheceriam Porto Alegre por morarem lá, e visitantes/estrangeiros que em breve estariam na cidade (linhas 168-169 e 176-195), estando imbricadas no design do curso, porém também no próprio contexto de sócio-histórico intercâmbio.

Conforme defende Buzato (2009), "novas tecnologias diversificam e complexificam continuamente as práticas de linguagem, os perfis dos sujeitos letrados e as ideologias sobre o papel da leitura e a escrita" (p. 5). Considerando a complexidade das ações em interação e dos modos de organização da participação nessa atividade pedagógica via chat, em evidente relação com a tarefa de leitura anterior realizada via wiki (vinculada à leitura de um site), podemos conceber essa atividade via chat como um evento de letramento estreitamente fomentado pelo design educacional do CEPI. Este design, apesar de passível de qualificação a partir de análises como a que aqui sistematizamos, parece fornecer um enquadramento para a realização de atividades pedagógicas orientadas por gêneros do discurso, promoção de letramentos e aprendizagem pela interação.

Como pode ser observado, a partir da análise de atividades sociais, podemos identificar aspectos para a edição dos materiais didáticos de modo a qualificar a atualização do construto teórico nas tarefas. Especialmente relacionado à análise da tarefa 3.1 e da atividade realizada, e partindo da proposta de ensino embasada no uso da linguagem em gêneros do discurso (BRASIL, 1998; DOLZ et al., 2004; Rojo, 2005; RS, 2009; SIMÕES et al., 2012; SCHLATTER; GARCEZ, 2012), por exemplo, argumenta-se ser necessário que a própria tarefa online ofereça recursos de modo a subsidiar a participação de alunos cujas trajetórias de letramentos se diferenciem da produção e participação esperadas, além da ponderação acerca da própria adequação (ajuste ao interlocutor) do convite aos alunos.

Concomitantemente, defendemos que os pressupostos teóricos que embasam um curso também precisam ser atualizados nas ações sociais dos participantes (não apenas no design), o que depende em grande medida da atuação do(a) professor(a) como orientador(a) de possíveis modos de participação e configuração de atividades pedagógicas. Destacamos, no entanto, a inexistência de apenas um modo de atualização do construto teórico, mas sim de modos sempre localmente construídos entre professores e alunos nos encontros educacionais.

Por fim, ressaltamos a necessidade de atenção ao falacioso poder de predeterminação do design educacional sobre a ação social: uma tarefa é um convite, mas este pode não ser 
aceito ou pode não ter sido um convite bem formulado. $\mathrm{O}(\mathrm{a})$ professor(a) precisa estar ciente dessas possibilidades, de modo a conseguir se posicionar como analista do que está acontecendo no aqui e agora das interações e intervir de modo responsivo e sensível às prováveis limitações do design, às diferentes trajetórias de letramentos (incluindo o digital) dos alunos e às potencialidades de aprendizagem emergentes das interações. Considerando ainda que cada grupo e cada interação possuem caráter único e singular, o(a) professor(a) precisa compreender a tarefa como um convite, que precisa ser interpretado, e as possibilidades de interpretação são amplas.

Assim, o design possui grande potencial de orientação das ações dos atores sociais, por isso nosso contínuo trabalho de elaboração de tarefas coerentes com os pressupostos teóricos e relevantes para os propósitos do curso e os contextos dos alunos - uma tarefa bemelaborada como a 3.2 tem o potencial de fomentar atividades pedagógicas profícuas para a aprendizagem de língua adicional pela interação, como pode ser observado. No entanto, não há determinismo entre tarefa e atividade: são os participantes, na relação que estabelecem com a tarefa durante a realização da atividade que irão colocar - ou não - as sugestões de planos de ação em prática, dando contornos próprios ao que estava previsto inicialmente.

\section{Considerações finais}

Com base na análise de dados, esperamos haver demonstrado como o design educacional deve considerar aspectos relacionados às práticas de linguagem que envolvem gêneros do discurso e suas relações com as trajetórias de letramento dos participantes dos cursos. Também destacamos a complexidade do trabalho de atualização do construto teórico aqui discutido tanto no design educacional quanto nas atividades de um curso online para a aprendizagem de línguas adicionais pela interação, orientado por gêneros do discurso e inteiramente a distância.

Ao assumirmos o caráter local e situado das relações entre design e atividades sociais, e admitirmos "que não apenas há letramentos diferentes em diferentes contextos, mas também que cada letramento e cada contexto é fundamentalmente heterogêneo, mutável e conectado a outros (i.e. dialógico)" (BUZATO, 2009, p. 5), nos encaminhamos para um redimensionamento do trabalho (a) de design educacional de cursos online, (b) de formação de professores para atuação em cursos online orientados por gêneros do discurso, letramentos e aprendizagem enquanto práticas sociais, e (c) de pesquisa sobre ensino e aprendizagem de 
línguas adicionais a distância.

\section{REFERÊNCIAS}

BAKHTIN, Mikhail. Estética da criação verbal. São Paulo: Martins Fontes, 2003.

BARAB, Sasha; KLING, Rob; GRAY, James H. (Org.). Designing for Virtual Communities in the Service of Learning. Cambridge: Cambridge University Press, 2004.

BRAGA, Denise B. Ambientes digitais: reflexões teóricas e práticas. São Paulo: Cortez, 2013.

BRASIL, Ministério da Educação e Cultura, Secretaria de Educação Fundamental. Parâmetros curriculares nacionais. Brasília: MEC/SEF, 1998.

BRASIL, Ministério da Educação e Cultura, Secretaria de Educação Superior. Manual do Exame Celpe-Bras. Brasília: MEC/SESu, 2011.

BRITTO, Luiz P. L. A sombra do caos: ensino de língua X tradição gramatical. Campinas: Mercado de Letras, 1997.

BULLA, Gabriela S. A realização de atividades pedagógicas colaborativas em sala de aula de português como língua estrangeira. Dissertação (Mestrado em Letras) - UFRGS, Porto Alegre, 2007.

BULLA, Gabriela S. Relações entre design educacional, atividade e ensino de português como língua adicional em ambientes digitais. Tese (Doutorado em Letras) - UFRGS, Porto Alegre, 2014.

BULLA, Gabriela S.; GARGIULO, Hebe; SCHLATTER, Margarete. Organización general de materiales didácticos para la enseñanza online de las lenguas: el caso del Curso de Español-Portugués para el Intercambio (CEPI). In: Anais II Jornadas Internacionales de Tecnologías aplicadas a la enseñanza. Córdoba: UNC, 2009. p. 1-12

BULLA, Gabriela S.; LEMOS, Fernanda C.; SCHLATTER, Margarete. Análise de material didático para o ensino de línguas adicionais a distância: reflexões e orientações para o design de tarefas pedagógicas. Revista Horizontes de Linguística Aplicada, v. 11, p. 103-135, 2012.

BULLA, Gabriela S..; UFLACKER, Cristina M.; SCHLATTER, Margarete. (Org.). Práticas pedagógicas e materiais didáticos para o ensino de Português como Língua Adicional. Porto Alegre: Editora da UFRGS, 2019.

BUZATO, Marcelo E. K. Letramento e inclusão: do estado-nação à era das TIC. DELTA, v. 25, n. 1, p. 1-38, 2009.

CLARK, Herb. Language use. In: CLARK, Herb (Org.). Using Language. Cambridge: 
Cambridge University Press, 1996. p. 3-25

COUGHLAN, Peter; DUFF, Patricia. Same task, different activities: analysis of SLA from an activity theory perspective. In: LANTOLF, James P.; APPEL, Gabriela. (Ed.). Vygotskian approaches to second language research. Norwood, NJ: Ablex, 1994. p. 173-194

COLLINS, Heloisa; FERREIRA, Anise. (Org.). Relatos de Experiência de Ensino e Aprendizagem de Línguas na Internet. Campinas: Mercado das Letras, 2004.

DOLZ, Joaquim; NOVERRAZ, Michèle; SCHNEUWLY, Bernard. Sequências didáticas para o oral e a escrita: apresentação de um procedimento. In: SCHNEUWLY, Bernard; DOLZ, Joaquim. (Org.). Gêneros Orais e escritos na escola. São Paulo: Mercado das Letras, 2004. p. 95-128

FARACO, Carlos A. Linguagem e diálogo: as ideias linguísticas do Círculo de Bakhtin. São Paulo: Parábola, 2009.

FONTES, Maria C. M. Aprendizagem de inglês via internet: descobrindo as potencialidades do meio digital. Tese (Doutorado em Linguística Aplicada e Estudos da Linguagem) Pontifícia Universidade Católica de São Paulo, São Paulo, 2002.

FREIRE, Maximina M. Complex educational design: a course design model based on complexity. Campus-Wide Information Systems, v. 30, n. 3, p. 174-185, 2013.

KLEIMAN, Angela. (Org.). Os significados do letramento: uma nova perspectiva sobre a prática social da escrita. Campinas: Mercado de Letras, 1995.

KRAEMER, Fernanda F. Português língua adicional: progressão curricular com base em gêneros do discurso. Dissertação (Mestrado em Letras) - UFRGS, Porto Alegre, 2012.

MONDADA, Lorenza; DOEHLER, Simona P. Second language acquisition as situated practice: Task accomplishment in the French second language classroom. Modern Language Journal, v. 88, n. 4, p. 501-518, 2004.

PAIVA, Vera L. M. O. et alii. Leitura em inglês na rede: a trajetória do projeto Ingrede.

Educação \& Tecnologia, Belo Horizonte, v. 17, n. 3, p. 19-37, 2012.

POLONIA, Eunice. Parâmetros para Procedimentos Pedagógicos na Aprendizagem de Inglês como Língua Estrangeira em uma Rede Telemática. Tese (Doutorado em Informática na Educação) - UFRGS, Porto Alegre, 2003.

RIO GRANDE DO SUL, Secretaria de Estado da Educação, Departamento Pedagógico. Referenciais curriculares do Estado do Rio Grande do Sul: linguagens, códigos e suas tecnologias. Porto Alegre: SE/DP, 2009.

ROJO, Roxane. Gêneros do discurso e gêneros textuais: questões teóricas e aplicadas. In:

MEURER, José L.; BONINI, Adair; MOTTA-ROTH, Désirée. (Org.). Gêneros, Teorias, 
métodos, debates. São Paulo: Parábola, 2005. p. 184-207

SADYKOVA, Gulnara; MESKILL, Carla. The Language of Digital Learning Objects: A Cross-disciplinary Study. MERLOT Journal of Online Learning and Teaching, v. 5, n. 2, p. 239-252, 2009.

SCHLATTER, Margarete; BULLA, Gabriela S; JURIC, Victor S., HRASTE, Margarita, RODRIGUEZ, Maria L. A Certificação de Espanhol e Português para o Intercâmbio (CEPI) como uma ação de política linguística no âmbito do Mercosul. In: Anais III Encuentro internacional de investigadores de políticas lingüísticas. Córdoba: AUGM, 2007. p. 59-64

SCHLATTER, Margarete; BULLA, Gabriela S.; GARGIULO, Hebe; JURIC, Victor S. La formación del profesor CEPI para interactuar en una comunidad colaborativa de aprendizaje a distancia. In: Anais II Jornadas Internacionales de Tecnologías aplicadas a la enseñanza. Córdoba: UNC, 2009. p. 1-18

SCHLATTER, Margarete; GARCEZ, Pedro M. Línguas adicionais na escola: aprendizagens colaborativas em Inglês. Erechim, RS: Edelbra, 2012.

SIMÕES, Luciene J. et alii. Leitura e autoria: planejamento em Língua Portuguesa e Literatura. Erechim, RS: Edelbra, 2012.

STREET, Brian. Literacy in Theory and Practice. Cambridge: Cambridge Univ. Press, 1984.

SUCHMAN, Lucy A. Human-Machine Reconfigurations: Plans and situated actions. 2 ed. Cambridge: Cambridge Univ. Press, 2007.

TELLES, João. (Ed.). Teletandem: Um contexto virtual, autônomo e colaborativo para aprendizagem de línguas no século XXI. Campinas: Pontes, 2009.

TERZI, Silvia B. A construção da leitura: uma experiência com crianças de meios iletrados. 2 ed. Campinas, SP: Pontes, 2001.

VOLOSHINOV, Valentin N. Marxism and the Philosophy of Language. Cambridge: Harvard University Press, 1973.

WARSCHAUER, Mark. Laptops and literacy: A multi-site case study. Pedagogies, v. 3, n. 1, p. 52-67, 2008.

WILEY, David A. (Ed.). The instructional use of learning objects. Bloomington, IN: AIT/AECT, 2002.

Recebido em 06/03/2020. Aceito em 19/05/2020. 